\title{
Corpora e metodologias ativas nas aulas de Prática de Tradução: duas experiências didáticas
}

\section{Corpora and active learning in Translation Practice classes: two didactic experiences}

\author{
Elisa Duarte Teixeira* \\ Joacyr T. de Oliveira*
}

* Professora Adjunta de Tradução - Inglês do Departamento de Línguas Estrangeiras e Tradução (LET) do Instituto de Letras da Universidade de Brasília - UnB e membro do Programa de Pós-Graduação em Tradução, POSTRAD, da mesma universidade. E-mail: elisadut@unb.br

** Docente de língua inglesa no CEL da Universidade Estadual de Campinas - UNICAMP. Doutor em Estudos Linguísticos e Literários pela Universidade de São Paulo - USP. E-mail: joacyr@unicamp.br 
Resumo: 0 uso de ferramentas computadorizadas na tradução vem promovendo uma verdadeira revolução no mercado de trabalho da área. Partindo da hipótese de que o ensino de tradução, pelo menos no Brasil, ainda está à procura de novas maneiras de incorporar essas tecnologias ao ensino e à prática da tradução no ambiente acadêmico, o presente trabalho apresenta duas experiências didáticas envolvendo metodologias ativas e o uso de corpora em disciplinas de Prática de Tradução. Em ambos os casos, os recursos tecnológicos e, em especial, os corpora eletrônicos compilados no decurso do semestre tiveram papel fundamental na dinâmica de trabalho do grupo. As ferramentas computadorizadas facilitaram o processo de aprendizagem e estimularam a aquisição de autoconfiança por parte dos aprendizes.

Palavras-chave: Ensino de tradução; Linguística de Corpus; Tradução Assistida por Computador (TAC); Corpus de aprendizes de tradução; Corpus comparável; Tradução especializada.

Abstract: The use of computerized tools in translation practice has revolutionized the job market in the area. Departing from the hypothesis that translator training, at least in Brazil, is still looking for new ways to incorporate these technologies in the teaching and practice of translation in the academic environment, the present work describes two didactic experiences involving active methodologies and the use of corpora in translation practice classes. In both cases, the technological resources and, in particular, the electronic corpora compiled by students during the semester played a quintessential role in the work dynamics of the group. The computerized tools facilitated the learning process and encouraged learner's self-confidence.

Keywords: Teaching translation; Corpus Linguistics; Computer-Assisted Translation (CAT); Learner translation corpus; Comparable corpus; Specialized translation.

TradTerm, São Paulo, v.37, n. 1, janeiro/2021, p. 88-118

Número Especial - Linguística de Corpus www.revistas.usp.br/tradterm 


\section{Introdução}

Neste século, ainda vivemos a revolução tecnológica. Os aparelhos digitais têm se tornado cada dia mais eficientes e a inteligência artificial é capaz de interagir com seres humanos e resolver problemas de modo habilidoso. A criação, o desenvolvimento e o aprimoramento de tradutores automáticos, por exemplo, têm se valido de resultados obtidos a partir do uso de algoritmos e da análise estatística de textos paralelos (original e respectiva(s) traduç(ão/ões)), organizados na forma de corpora eletrônicos, para sugerir equivalentes tradutórios. Sem dúvida, já avançamos muito com relação ao desempenho desses tradutores, mas, como apontam Barreiro et al. (2014), o produto da tradução automática é de qualidade "pouco fiável”, já que a inteligência artificial ainda não é capaz de "ler" e "interpretar" um texto da mesma forma que um tradutor humano. Assim, parece seguro afirmar que a figura do profissional da tradução continuará mantendo seu protagonismo no mercado. Tal prenúncio encontra respaldo no aumento de oferta de bacharelados em Tradução em Instituições de Ensino Superior ${ }^{1}$ (IES). Um comparativo feito com base nos dados coletados pelo Censo da Educação Superior realizado pelo Instituto Nacional de Estudos e Pesquisas Educacionais Anísio Teixeira (INEP), nos anos 2008 e 2018, mostra que o número de instituições que oferecem o bacharelado em Tradução, bem como o número de alunos frequentando esse curso, mais do que dobrou (Quadro 1). Além dos cursos presenciais, nos dados de 2018 há também informações sobre uma graduação a distância.

Em 2008, o referido Censo registrou que apenas seis instituições ofereciam o bacharelado em Tradução no país, atendendo 1.535 alunos. Após dez anos, em 2018, o número de IES que contavam com tal graduação passou para 19, com 3.732 alunos matriculados. Esse aumento gerou uma maior demanda por professores para as disciplinas específicas, entre elas as que desenvolvem a habilidade tradutória, chamando a atenção para os docentes

\footnotetext{
1 Segundo o INEP, é considerada uma Instituição de Ensino Superior a universidade, centro universitário ou faculdade que oferece cursos de graduação e sequenciais de formação específica.
}

TradTerm, São Paulo, v.37, n. 1, janeiro/2021, p. 88-118

Número Especial - Linguística de Corpus

www.revistas.usp.br/tradterm 
desses cursos e suas metodologias de ensino.

Quadro 1: Dados do Censo de Educação Superior do INEP dos anos de 2008 e 2018.

\begin{tabular}{|c|c|c|c|c|c|c|c|c|}
\hline & \multicolumn{6}{|c|}{ Instituições de Ensino Superior (IES) } & \multicolumn{2}{|c|}{ Totais } \\
\hline & Pública & $\mathrm{N}^{0} \cdot \mathrm{de}$ & alunos & Privada & $\mathrm{N}^{0} \cdot \mathrm{de}$ & lunos & IES & Alunos \\
\hline Ano & & Presencial & Distância & & Presencial & Distância & & \\
\hline 2008 & 1 & 682 & -- & 5 & 853 & -- & 6 & 1.535 \\
\hline 2018 & 7 & 1.299 & -- & 12 & 1.681 & 752 & 19 & 3.732 \\
\hline
\end{tabular}

Fonte: a autora e o autor.

Com suas devidas exceções, tradicionalmente as disciplinas de prática de tradução são ministradas por professores transmissionistas, ou seja, que assumem o papel de detentores do conhecimento e juízes do que é certo ou errado na tradução (como se isso fosse possível!). O aluno é relegado a um papel coadjuvante e se posiciona como elemento passivo, que apenas recebe instruções. Numa sala de aula como essa, o aprendiz deve ouvir as ponderações do professor sobre as possíveis problemáticas da tradução e soluções aceitáveis e, idealmente, mais tarde, sozinho, voltar ao seu texto e decidir se suas soluções estão ou não dentro dos padrões estabelecidos.

Dados obtidos por meio de uma pesquisa realizada por Esqueda (2018) com docentes de Tradução no Brasil mostram que a prática de aulas centradas no professor ainda é comum. Durante as entrevistas, muitos professores afirmaram que, após distribuírem os textos para serem trabalhados em casa, durante a aula, "chamavam" alguns alunos para lerem sua tradução e serem avaliados. A pesquisadora entrevistou 13 deles em 2012 e, posteriormente, em 2017, para conhecer suas práticas pedagógicas, do que concluiu:

\section{(...) a pedagogia vigente no ensino da prática da tradução, em se tratando do universo investigado, parece ainda se pautar na conferência magistral, ou seja, as atividades realizadas pelos alunos contam muito pouco na cena pedagógica, pois, em última instância, eles deverão obedecer às soluções de tradução propostas pelo professor. (ESQUEDA 2018: 1268)}

As evidências obtidas por meio dos resultados da pesquisa de Esqueda (2018) revelam que a "didática magistral" ainda está presente nos bacharelados de Tradução. Tais indícios corroboram a necessidade de se revisitar o cenário atual e propor mais práticas pedagógicas alternativas que, principalmente, realoquem o aluno a uma posição de atuação mais central na

TradTerm, São Paulo, v.37, n. 1, janeiro/2021, p. 88-118 Número Especial - Linguística de Corpus www.revistas.usp.br/tradterm 
sala de aula.

Partindo da premissa de que uma nova realidade profissional, permeada pela tecnologia, tem se imposto aos tradutores profissionais e em formação, em especial na última década, nosso objetivo com este artigo não é avaliar se as metodologias mais tradicionais são ou não adequadas a esse novo cenário de trabalho, mas promover uma reflexão sobre práticas alternativas que possam ser empregadas por professores nas disciplinas de tradução. Para tanto, vamos apresentar duas experiências didáticas: uma proposta metodológica que compreende uma tarefa de tradução com base em corpora de aprendizes (seção 4) e o relato de uma tarefa de tradução colaborativa baseada em projeto autêntico realizada por uma turma de prática de tradução especializada, envolvendo o uso de corpora comparáveis e ferramentas de TAC (seção 5). Antes de passarmos aos relatos propriamente, apresentamos, a seguir, um pequeno apanhado das noções fundamentais das abordagens empregadas em ambos os casos: a Linguística de Corpus e as metodologias ativas de ensino.

\section{A parceria Linguística de Corpus e Tradução}

A Linguística de Corpus (doravante LC), abordagem empirista da linguagem que a estuda por meio da observação de exemplos autênticos de uso com o auxílio de ferramentas computadorizadas, se popularizou no meio acadêmico com o surgimento do microcomputador, a partir dos anos 1980, como afirmam vários autores ( $c f$, p. ex., Berber SARDinHA 2004: 5). Mas os primeiros registros de sua associação à teoria e à prática da tradução, salvo engano, são de autoria de Mona Baker. Em 1993, a autora publicou um artigo em que advoga, com propriedade, o emprego da LC na recém-inaugurada disciplina dos Estudos da Tradução. No ano anterior, ela havia publicado um livro fundador para a área (BAKER 1992), em que fica clara a influência que tiveram os estudos seminais em LC, tanto monolíngues (p. ex. SINCLAIR 1991) quanto contrastivos (p. ex. JOHANSSON 1998), em seu entendimento sobre o funcionamento da linguagem e da tradução.

No Brasil, uma das pioneiras na associação da LC aos Estudos da

TradTerm, São Paulo, v.37, n. 1, janeiro/2021, p. 88-118 Número Especial - Linguística de Corpus www.revistas.usp.br/tradterm 
Tradução foi a Profa. Dra. Stella Tagnin, da Universidade de São Paulo (USP). Em meados da década de 1990, começou a divulgar as novidades da área entre seus pares brasileiros após voltar de um período de estudos na Europa. Incorporou a LC nas aulas que ministrava no Departamento de Línguas Modernas da USP, onde trilhou sua carreira docente, e no antigo curso de Especialização de Longa Duração em Tradução da mesma instituição. Aos poucos, foram surgindo também trabalhos de mestrado e doutorado orientados por ela abordando a associação entre LC e Tradução.

Em termos de metodologia de ensino de tradução, a LC parece ter se popularizado mais, e primeiramente, no ensino de tradução especializada e de Terminologia, no Brasil, haja vista sua utilidade evidente nessa área correlata. No entanto, seu uso profícuo foi atestado inúmeras vezes também no ensino de tradução de textos chamados "gerais" (como este artigo espera corroborar - vide também OLIVEIRA 2014 e TAGNIN 2015, p. ex.). Com relação às traduções literárias, a LC tem sido tradicionalmente empregada no estudo dos universais da tradução propostos por Baker (1993, p. 243) e seus seguidores, mas há diversos estudos demonstrando sua eficácia também na análise comparativa e contrastiva de características textuais variadas de textos de partida literários e sua(s) respectiva(s) traduç(ão/ões) (cf., p. ex., GONçALVES 2006).

Antes de apresentarmos nossas contribuições para o ensino de tradução utilizando a abordagem da LC, revisitamos alguns conceitos fundamentais das metodologias ativas de ensino e sua aplicação ao ensino de tradução, a seguir.

\section{Metodologias ativas no ensino de tradução}

Há algum tempo, professores têm debatido e refletido sobre os níveis de aprendizagem resultantes do emprego de metodologias de ensino de tradução mais tradicionais, em que o professor é o detentor do saber, como mencionado anteriormente. 0 papel do educador tem sido repensado e um dos desafios que emergem nesses debates é como o professor pode se deslocar do papel de transmissor de conhecimentos para um lugar de orientador, não só do conhecimento que o aluno traz para a aula, mas 
também de sua busca por novas aprendizagens. Nesse cenário, colocam-se questões sobre a adoção de metodologias de ensino que promovam e propiciem a participação do aluno em seu processo de aprender. As metodologias ativas, por colocarem o foco da aula no estudante e designarem ao professor a função de orientador da aprendizagem, têm se mostrado uma boa alternativa a metodologias mais tradicionais.

0 planejamento pedagógico de uma disciplina baseada em metodologias ativas posiciona o aluno como agente em seu próprio aprender e colaborador do aprender do colega. O professor, ao orientar e instrumentalizar o aluno na construção de seu conhecimento, focado na autonomia e na criticidade, também reflete sobre suas práticas e avalia os resultados, que podem assegurar a continuidade dos processos, ou a discussão sobre possíveis mudanças (OLIVEIRA 2019).

As pesquisas de educadores construtivistas nos mostram que o processo de aprendizagem envolve adquirir novos conhecimentos e revisitar conhecimentos prévios, seja para expandi-los ou revisá-los. O aluno, como protagonista, encontra oportunidades de envolvimento com todo o processo pedagógico e fortalece a sua visão positiva do aprender. Em um estudo desenvolvido por Hyun, Ediger e Lee (2017), foi feita uma avaliação sobre a satisfação do aluno em relação à sua aprendizagem por meio tanto de metodologias tradicionais quanto ativas. Os resultados demonstraram que as atividades pedagógicas que envolviam a colaboração discente impactaram de forma positiva o grau de contentamento dos alunos.

Dentro das metodologias ativas há várias estratégias de aplicação de atividades pedagógicas, dentre as quais Morán (2015: 21) destaca:

(...) Aprendizagem por pares (Peer Instruction), por times e outros. O Peer Instruction é uma das metodologias inovadoras aplicadas por professores nos diversos cursos. Outros métodos utilizados são PBL Project Based Learning (aprendizagem por meio de projetos ou de problemas); TBL -Team-based Learning (aprendizagem por times), WAC - Writing Across the Curriculum (escrita por meio das disciplinas) e Study Case (estudo de caso).

TradTerm, São Paulo, v.37, n. 1, janeiro/2021, p. 88-118 Número Especial - Linguística de Corpus www.revistas.usp.br/tradterm 
Certamente, outras estratégias poderiam ser adicionadas à lista sugerida por Morán (2015). Uma delas é a Sala de Aula Invertida, ou Flipped Classroom, em que o aluno é exposto a uma série de pré-tarefas que visam prepará-lo para o conteúdo que será desenvolvido em aula (cf. BERGMANN; SAMS 2012).

As disciplinas de prática de tradução oferecem diversas oportunidades para a implementação de metodologias ativas, desde a colaboração discente na escolha do texto a ser traduzido, por exemplo, à discussão da tarefa proposta, análise das traduções em grupos etc. Vale ressaltar que há uma questão terminológica que demanda estudo mais aprofundado na área de Estudos da Tradução. É preciso distinguir, dentre as metodologias ativas de ensino de tradução, a "sala de aula colaborativa" ou "atividades colaborativas", dos "projetos de tradução colaborativa”. No primeiro caso, estamos falando de um ambiente de ensino em que os alunos compartilham conhecimento, colaborando com a aprendizagem do colega, construindo uma rede de conhecimento que extrapola a individualidade e se conecta ao saber do outro. No caso de projetos ou traduções chamados "colaborativos", estamos nos referindo a uma determinada atividade de tradução que é feita “a várias mãos” e de forma integrada e cooperativa.

Nas próximas seções, descrevemos duas propostas de metodologia que propiciam o envolvimento do aluno no processo pedagógico.

\section{Corpora de aprendizes nas aulas de prática de tradução}

A experiência didática relatada nesta seção pormenoriza um método de aprendizagem resultante dos mais de 14 anos de ensino de prática de tradução do coautor deste trabalho. O foco de tal método está nos corpora de aprendizes, mais precisamente naqueles compilados a partir das traduções produzidas por alunos em sala de aula. Ao definir os corpora de aprendizes de idiomas, Granger (2008) afirma que tal modalidade, seguindo critérios bem rígidos de seleção, contempla uma coleção eletrônica de dados naturais, ou

\footnotetext{
TradTerm, São Paulo, v.37, n. 1, janeiro/2021, p. 88-118 Número Especial - Linguística de Corpus www.revistas.usp.br/tradterm
} 
quase naturais, produzidos por estudantes de língua estrangeira. Ao expandir a definição de Granger (2008) para os corpora de aprendizes de Tradução, deve-se ter em mente que sua compilação inclui textos em duas línguas, sendo que ao menos uma delas é estrangeira, e dispostos paralelamente, possibilitando o cotejo entre original e tradução. Além disso, em um corpus de aprendizes, o texto de partida e a tarefa de tradução proposta regem as características dos textos de chegada. Ou seja, o corpus é formado por vários subcorpora, gerados a partir de tarefas específicas. Tais características tornam o corpus de aprendizes, per se, um material com muitas possiblidades de uso em atividades didáticas.

\subsection{Sala de aula colaborativa para ensino de tradução}

Ao optar por metodologias ativas, todo o processo, da escolha do texto até o desenvolvimento da atividade em sala, envolve a participação do aluno. Dentre as várias possibilidades para a implementação de tarefas colaborativas, a estratégia de ensino proposta por Oliveira (2019) sugere seis passos, a saber: a) seleção do texto de partida; b) elaboração da tarefa; c) compilação do corpus; d) análise do corpus como insumo do plano de aula; e) cotejo das traduções; e f) avaliação. A seguir, detalhamos melhor cada uma delas.

\subsubsection{Seleção do texto de partida}

Na sala de aula ativa, os alunos participam da escolha do texto que será trabalhado. 0 professor, ao assumir o papel de coordenador e facilitador, orienta os alunos no estabelecimento dos quesitos necessários para a seleção do texto. Em seguida, em pares ou pequenos grupos, os alunos escolhem com qual texto preferem trabalhar. Nesse momento é possível fazer uma previsão das problemáticas tradutórias envolvidas e as possíveis estratégias que poderiam ser aplicadas.

TradTerm, São Paulo, v.37, n. 1, janeiro/2021, p. 88-118 Número Especial - Linguística de Corpus www.revistas.usp.br/tradterm 


\subsubsection{Elaboração da tarefa}

A escolha do texto de partida determina os tipos de competência tradutória envolvidas (cf. PACTE 2003), assim como as questões lexicais, morfossintáticas e tipologias textuais. Neste ponto, o professor tem como opção favorecer uma ou mais das estratégias sugeridas dentro das metodologias ativas. Vale ressaltar, entretanto, que as instruções que guiarão a atividade devem ser claras e detalhadas. Por exemplo, podemos elencar as exigências de um cliente imaginário, determinar quem será o público-leitor, onde o texto será publicado, estabelecer o número máximo de palavras, entre outras. Tais orientações são fundamentais, pois, no último passo, servirão de parâmetros, tanto aos alunos quanto ao professor, para avaliar se os objetivos da tarefa foram ou não atingidos.

\subsubsection{Compilação do corpus}

Após planejar, discutir e elaborar a tarefa, temos que determinar como o texto será enviado aos alunos e como as traduções serão devolvidas ao professor. Tal processo pode ser feito automaticamente com o uso do Formulário Google, disponibilizado gratuitamente no portal da Google. Inicialmente devemos segmentar o texto original tendo como parâmetro os períodos sintáticos, ou seja, cada período é equivalente a um segmento. Em seguida, criamos um Formulário Google e inserimos cada segmento do original em uma pergunta do tipo "resposta curta”. O formulário, então, é disponibilizado ao aluno, que deverá inserir a tradução dos segmentos nos campos de resposta. É aconselhável estabelecer uma série de códigos que o aluno deve usar para indicar omissões, junções e separações de segmentos e parágrafos. Após o envio, o próprio sistema do Formulário Google coleta as traduções e as direciona para uma planilha eletrônica onde cada segmento do texto de chegada é alinhado com o segmento ao qual se refere no texto de partida. Além do alinhamento, a flexibilidade no uso de colunas e linhas e a possiblidade de uso de filtros e fórmulas tornam a planilha eletrônica um instrumento didático muito prático para a sala de aula. Oliveira $(2014,2019)$ discute detalhadamente todo esse processo.

TradTerm, São Paulo, v.37, n. 1, janeiro/2021, p. 88-118

Número Especial - Linguística de Corpus

www.revistas.usp.br/tradterm 


\subsubsection{Análise do corpus como insumo do plano de aula}

Os resultados da análise de um corpus de aprendizes podem ser utilizados pelo menos de duas formas: a) para fazer um levantamento sobre as dificuldades linguísticas e estratégicas dos alunos, que servem de insumo para o plano de aula; e b) como material didático autêntico para ser usado durante a aula.

Uma vez que as traduções foram enviadas e a planilha eletrônica foi gerada automaticamente no Google Drive, a análise dos segmentos é muito prática, pois na primeira linha temos os segmentos de partida e, dispostos nas linhas de baixo, na mesma coluna, os segmentos de chegada. A Erro! Fonte de referência não encontrada. mostra um exemplo de segmentos de partida na linha “1” (em vermelho) e suas traduções logo abaixo. 0 uso da ferramenta de filtro facilita a análise, pois é possível configurá-la para que busque segmentos com determinadas características. ${ }^{2}$

Figura 1: Dois segmentos do texto de partida e suas traduções na planilha eletrônica.

\begin{tabular}{|c|c|c|}
\hline & Y & z \\
\hline 1 & $\begin{array}{l}\text { Alguns membros da equipe tinham um estranho pressentimento, } \\
\text { como se algo de ruim estivesse para acontecer. }\end{array}$ & $\begin{array}{l}\text { Parecia que uma força maligna e incontrolável estava } \\
\text { prestes a ser libertada. }\end{array}$ \\
\hline 2 & $\begin{array}{l}\text { A few members of the team had a weird felling like if something } \\
\text { bad was about to happen }\end{array}$ & $\begin{array}{l}\text { It seemed like an evil and uncontrollable force was about to } \\
\text { be released }\end{array}$ \\
\hline 3 & $\begin{array}{l}\text { Some party members had a strange feelling, as if something bad } \\
\text { was about to happen }\end{array}$ & It looked like a evil and unstoppable force will be released \\
\hline 4 & $\begin{array}{l}\text { Some team members had a strange feeling, as if something bad } \\
\text { was about to happen. }\end{array}$ & $\begin{array}{l}\text { It seemed like a evil, uncontrollable force was about to be } \\
\text { released. }\end{array}$ \\
\hline 5 & $\begin{array}{l}\text { Some members of the staff had a strange premonition, as if } \\
\text { something bad was about to happen. }\end{array}$ & $\begin{array}{l}\text { It seems that a malign and uncontrollable force was about } \\
\text { to be released. }\end{array}$ \\
\hline 6 & $\begin{array}{l}\text { Some team members would have a bad feeling as though } \\
\text { something bad was about to happen. }\end{array}$ & $\begin{array}{l}\text { It seemed like a maligne and uncontrolled force that was } \\
\text { about to be released. }\end{array}$ \\
\hline 7 & $\begin{array}{l}\text { Some members of the team had an odd feeling, as if something } \\
\text { bad was going to happen. }\end{array}$ & $\begin{array}{l}\text { It seemed like an evil and unstoppable force was about to } \\
\text { be released. }\end{array}$ \\
\hline 8 & $\begin{array}{l}\text { Some members of the team had a strange feeling, as if something } \\
\text { bad were about to happen. }\end{array}$ & $\begin{array}{l}\text { It seems like an evil and uncontrollable force was about to } \\
\text { be released. }\end{array}$ \\
\hline 9 & $\begin{array}{l}\text { Some members of the team was having a strange feeling, as } \\
\text { something very bad could happen. }\end{array}$ & $\begin{array}{l}\text { It seems like some evil and uncontrollable power were } \\
\text { ready to come loose. }\end{array}$ \\
\hline 10 & $\begin{array}{l}\text { Some of the team members had a bad feeling like something was } \\
\text { about to happen. }\end{array}$ & $\begin{array}{l}\text { It felt like an evil and uncontrollable force was about to be } \\
\text { unleashed. }\end{array}$ \\
\hline
\end{tabular}

Fonte: o coautor.

\footnotetext{
2 Existe uma vasta documentação disponibilizada gratuitamente na Internet sobre como usar a ferramenta de filtro da planilha eletrônica com conteúdos textuais.
} 
Ao identificar as inadequações, o professor deve separá-las em dois grupos: eventos com baixa frequência, que talvez só valha a pena tratar se foram recorrentes em outros textos, e eventos com alta frequência, que deverão fazer parte do plano de aula.

\subsubsection{Cotejo das traduções}

Com os dados da análise feita durante a preparação da aula, o professor tem a oportunidade de aplicar a estratégia de sala de aula invertida. Anteriormente à aula em que haverá o cotejo da tradução, os alunos são incumbidos de pesquisar sobre os itens detectados como dificuldades linguísticas. Durante a aula, trabalhando em pares ou grupos, os alunos inicialmente compartilham os achados de sua pesquisa linguística e, em seguida, leem as traduções, buscando identificar as inadequações.

Uma questão a ser resolvida neste passo é o acesso às traduções. Se a aula ocorre em um laboratório de informática, basta o acesso ao arquivo com as traduções alinhadas. Se isso não for possível, pode-se pedir para que os alunos acessem o arquivo usando tecnologia própria, como celulares, tablets ou laptops.

O próximo passo é o cotejo de cada segmento utilizando o corpus disposto na planilha eletrônica, por meio de projeção ou computadores individuais. Uma opção colaborativa é o trabalho em pares ou trios a fim de viabilizar a discussão e a troca de conhecimento, principalmente se os níveis de proficiência linguística forem muito díspares. Após justificarem o porquê de algumas traduções estarem inadequadas, os alunos trabalham em duplas ou grupos para sugerir melhorias. Outra vantagem do uso da planilha em aula é que todos os alunos têm a sua tradução contemplada pelo professor e pelos colegas, o que também proporciona a troca de ideias e reflexões sobre suas escolhas e as dos colegas. Ou seja, em uma sala colaborativa todos os participantes (e não apenas o professor) formam o "público-leitor" da tradução.

TradTerm, São Paulo, v.37, n. 1, janeiro/2021, p. 88-118 Número Especial - Linguística de Corpus www.revistas.usp.br/tradterm 


\subsubsection{Avaliação}

Ao final da atividade, os alunos devem usar as instruções da tarefa como critérios para julgar se todos os requisitos foram cumpridos. Neste momento também deve-se fazer uma avaliação das estratégias adotadas, tanto para pesquisas linguísticas quanto para solucionar as problemáticas de tradução. O professor também deve fazer parte do processo avaliativo, refletindo sobre os pontos fortes e fracos da atividade como um todo e quais elementos devem ser repetidos ou evitados na tarefa seguinte. O ideal é que tais reflexões sejam registradas de alguma forma (um formulário Google poderia ser usado e todas as respostas armazenadas em uma planilha) e acessadas em um momento futuro, talvez para a avaliação institucional da disciplina ou algum outro processo avaliativo.

O trabalho em pares e/ou grupos propicia a solução de problemas e enriquece o aprendizado, tornando o aprender significativo: o aluno sabe onde está, planeja onde pretende chegar e, no final, avalia se obteve sucesso. Observamos que atividades colaborativas como as descritas nesta experiência didática empoderam os alunos e os colocam não só no controle de sua própria aprendizagem, mas também como elementos participativos e responsáveis pela aprendizagem dos colegas.

A seguir, apresentamos uma experiência didática utilizando a metodologia ativa de ensino em uma turma de prática de tradução português -> inglês de textos especializados.

\section{Tradução colaborativa com o apoio da LC}

Nesta seção, vamos relatar uma experiência didática de tradução colaborativa de abordagem "baseada em projeto" envolvendo o uso da LC e de ferramentas de Tradução Assistida por Computador (TAC). Uma tradução baseada em projeto ocorre quando aprendizes e professor assumem, coletivamente, a responsabilidade de comissionar um trabalho autêntico de tradução de grande porte (cf. VIENNE 1994; HuRTAdo AlBIR 1999; KIRALY 2000, 2005 e 2012; GonZÁlez-Davies 2003, 2004 e 2017; GouadeC 2003; Kelly 2005; Galán-Mañas 2011; Colina e Venuti 2017; Malta e Teixeira, no prelo). Autores TradTerm, São Paulo, v.37, n. 1, janeiro/2021, p. 88-118 Número Especial - Linguística de Corpus 
que já passaram por essa experiência ressaltam que há algumas vantagens e limitações a se considerar antes de se empreender um projeto dessa natureza, de complexidade multifacetada inerente:

i. os problemas de tradução e logística que surgirem serão reais, e não fictícios - isso, por um lado, exige grande responsabilidade por parte do grupo, mas, por outro, resulta num ganho maior de autoconfiança, já que estimula a autonomia dos estudantes;

ii. por se tratar de uma tradução real, há mais motivação por parte dos aprendizes, pois o projeto representa, para muitos, a primeira experiência "profissional" de tradução, algo que poderão acrescentar a seus currículos, mas há também o fato de ser um trabalho de grande demanda e responsabilidade, muitas vezes sem compensação financeira;

iii. por visar o desenvolvimento de competências tradutórias e profissionais por meio da prática de tradução, esse tipo de atividade deve ser reservado a discentes dos últimos semestres do curso, mais experientes;

iv. a carga de trabalho para a/o docente e, ocasionalmente, para as/os discentes tende a ser muito maior do que seria numa situação de sala de aula normal;

v. a empreitada exige um esforço coletivo e a participação ativa e orquestrada de toda/os - o que nem sempre é a realidade numa sala de aula heterogênea e sujeita a imprevistos pessoais e acadêmicos do semestre.

0 projeto que vamos relatar aqui consistiu em traduzir, do português ao inglês, na disciplina de Prática de Tradução Português->Inglês: Textos Técnicos e Científicos (doravante Versão: técnicos), do Bacharelado em Tradução da Universidade de Brasília, ministrada pela coautora deste artigo, um livro que tem a Arquitetura como temática central. Nas subseções a seguir, detalhamos esse processo e comentamos os resultados alcançados, dos pontos de vista metodológico e didático.

TradTerm, São Paulo, v.37, n. 1, janeiro/2021, p. 88-118 Número Especial - Linguística de Corpus www.revistas.usp.br/tradterm 


\subsection{O projeto de tradução}

No início do primeiro semestre de 2017, a coautora foi procurada pela editora-chefe da Editora da Universidade de Brasília para traduzir, do português para o inglês, um livro publicado pela Editora em 2014, para celebrar os 50 anos da criação da Universidade (SCHLEE et al, 2014). A obra, elaborada por um grupo de docentes da instituição, apresenta um apanhado histórico e as principais características arquitetônicas de cinquenta de seus edifícios mais icônicos. A ideia da editora-chefe era traduzir o material também para o espanhol e o francês para compor uma coletânea, juntamente com o texto original, a ser apresentada como presente institucional.

Diante da indisponibilidade de tempo para assumir tal projeto à época, e da inexperiência da coautora na área de Arquitetura, surgiu uma proposta ousada - traduzir a obra coletivamente na disciplina de Prática de Tradução Português->Inglês: Textos técnicos e científicos, que estava ministrando naquele semestre. A editora-chefe, formada em Letras - Tradução e atuante na área, aceitou de bom grado o desafio. Como compensação, ofereceu um valor simbólico pela coordenação do projeto e um vale-livro para cada um dos alunos participantes. Todos os vinte discentes matriculados na disciplina, ao serem apresentados ao projeto (com a opção de não participarem, caso não se sentissem confortáveis ou interessados), "abraçaram" voluntariamente a empreitada, mostrando-se bastante entusiasmados, ainda que um tanto inseguros. A seguir, descrevemos o passo-a-passo seguido até a publicação do livro traduzido.

\subsection{Organização e divisão das tarefas}

O primeiro passo, antes mesmo de começar a planejar e distribuir a tarefa de tradução ao longo do semestre, foi pedir aos alunos que assinassem um termo de responsabilidade em que afirmavam, entre outras coisas: que sua participação era voluntária; que assumiam a responsabilidade de entregar suas tarefas nos prazos estipulados e que isso faria parte de sua avaliação final na disciplina; e que estavam cientes de que o trabalho não seria remunerado em espécie. Este passo foi fundamental para despertar neles o

TradTerm, São Paulo, v.37, n. 1, janeiro/2021, p. 88-118 Número Especial - Linguística de Corpus www.revistas.usp.br/tradterm 
senso de responsabilidade e para que percebessem a importância do trabalho em equipe para que o projeto fosse bem sucedido.

A etapa seguinte consistiu em criar subgrupos de trabalho para cuidar de diversas tarefas preparatórias para a tradução em si, a saber: i) elaboração de um briefing de tradução; ii) preparo e distribuição dos originais; iii) levantamento inicial do vocabulário especializado no texto de partida; iv) coleta e organização de materiais de apoio. Os alunos ficaram livres para escolher as tarefas com as quais tinham mais afinidade e se organizaram para coordenar os trabalhos, com apoio da docente. Seu progresso, as dúvidas e problemas que iam surgindo eram discutidos e resolvidos em sala de aula, cujos encontros foram mantidos duas vezes por semana, ou por e-mail.

Os responsáveis pela criação do briefing de tradução contactaram a Editora e se reuniram com os responsáveis para coletar mais detalhes sobre o projeto editorial. Os parâmetros de especificação de projetos de tradução sugeridos por Durban e Melby (2007) e Olohan (2016: 18-21) serviram de apoio para levantar questões relativas a:

a. público-alvo;

b. finalidade da tradução;

c. prazo de entrega;

d. orçamento;

e. área temática e tipo textual;

f. língua e variante regional dos textos de partida e de chegada;

g. formato;

h. volume de trabalho (caracteres / palavras / laudas);

i. etapas da produção (tradução, cotejamento com o original, revisão do texto de chegada, revisão de especialista, etc.).

Os dados resultantes desse encontro foram apresentados em sala de aula e discutidos com os demais alunos.

À equipe responsável pelo preparo e distribuição dos originais tocou converter o arquivo em .pdf enviado para o formato de texto (.docx), fazendo os ajustes necessários (p. ex., retirar marcas de parágrafo falsas). 0 programa gratuito que apresentou melhor desempenho nessa tarefa, segundo o relato 
dos alunos, foi o Smallpdf ${ }^{3}$. Em seguida, separaram o texto em capítulos e apresentaram a contagem de caracteres, para que se pudesse calcular 0 quanto caberia, em termos de laudas (de 1.350 caracteres, incluindo espaços), para cada aluno.

O livro de 152 páginas e 64 capítulos (cerca de 190.000 caracteres / 142 laudas) foi dividido entre os estudantes, que ficaram responsáveis por 6 a 10 laudas cada - a variação ficou por conta do tamanho irregular dos capítulos, que optamos por não segmentar, e do nível de dificuldade do conteúdo especializado. Também foi providenciada uma fotocópia física do original (ricamente ilustrado), que foi desmembrada e distribuída em sala entre os responsáveis pela tradução de cada parte.

O grupo foi dividido em "duplas de tradução", escolhidas pelos discentes, em que cada um traduziria a parte que the foi designada e, em seguida, trocaria esta sua primeira versão da tradução com o parceiro de dupla, e vice-versa. Este faria uma conferência com o original (cotejamento) e uma primeira leitura do texto traduzido, para identificar possíveis problemas tradutórios e terminológicos, prioritariamente. As traduções revisadas seriam então destrocadas e, após cada tradutor rever os comentários e sugestões do colega de dupla, aceitando-as ou não, enviariam os textos revisados da dupla para uma "dupla de revisão", recebendo o trabalho desta dupla para revisar também.

Cada membro da "dupla de revisão" deveria reler a tradução recebida, identificando possíveis problemas de ortografia, gramática, coesão e coerência etc. no texto de chegada, passar para o colega de dupla fazer mais uma leitura e depois devolver para o tradutor que produziu o texto, com comentários suplementares, em caso de mudança substancial e/ou alteração de terminologia. Depois de receber seus textos de volta, cada tradutor faria uma quinta e última leitura de seu texto e enviaria o arquivo finalizado para a docente. No que se segue, descrevemos como foi feita a preparação do material de consulta utilizado durante a tradução.

3 Disponível em: https://smallpdf.com/. Infelizmente, o serviço passou a ser pago recentemente.

TradTerm, São Paulo, v.37, n. 1, janeiro/2021, p. 88-118 Número Especial - Linguística de Corpus www.revistas.usp.br/tradterm 


\subsection{Corpus especializado e materiais de apoio}

Levando-se em conta que nenhum aluno do grupo era especialista e/ou atuante na área de Arquitetura (com exceção de um, que desistira do curso no último semestre e que nos auxiliou bastante nas questões terminológicas), a etapa preparatória seguinte foi compilar um corpus eletrônico de apoio à tradução contendo textos semelhantes, em temática, ao que estávamos prestes a produzir na língua de chegada. Ainda que a compilação de corpora chamados "comparáveis" descrita na literatura, em geral, envolva a coleta de textos com características semelhantes em duas ou mais línguas, optamos por coletar inicialmente apenas textos na língua de chegada (inglês), devido a restrições de tempo. Nesse sentido, o corpus compilado se assemelha mais ao que Krista Varantola (2002) e Belinda Maia (2002) chamaram de "disposable corpora" (corpora descartáveis), criados para auxiliar numa tarefa de tradução específica.

A criação de um corpus especializado comparável na língua de chegada para servir de apoio à tarefa tradutória demandava conhecer que tipo de terminologia e de padrões linguísticos recorrentes estavam presentes no texto de partida. Assim, já de posse de suas respectivas laudas, os alunos foram solicitados a fazer uma leitura integral do seu excerto para levantar manualmente o que consideravam ser unidades de tradução especializadas. Os resultados foram discutidos em sala de aula e anotados em um arquivo de acesso coletivo. Em seguida, foi feito um levantamento semiautomático de candidatos a termo utilizando recursos informatizados de exploração de corpora de uso gratuito, dentre os quais destacamos o AntConc (ANTHONY, 2014).

Utilizando o AntConc, fizemos uma lista de palavras (Wordlist) do original e, em seguida, a comparamos com a lista de palavras do corpus de referência Lácio-Ref (ALuísıo et al. 2003), para extrair as palavras-chave do texto de partida. Um corpus de referência costuma ser de língua geral e pelo menos cinco vezes maior que o corpus de estudo; é usado como termo de comparação pela ferramenta Keyword List, cuja tela inicial de resultado pode ser vista na Figura 2.

TradTerm, São Paulo, v.37, n. 1, janeiro/2021, p. 88-118 Número Especial - Linguística de Corpus www.revistas.usp.br/tradterm 
Figura 2: Palavras-chave do texto de partida no AntConc.

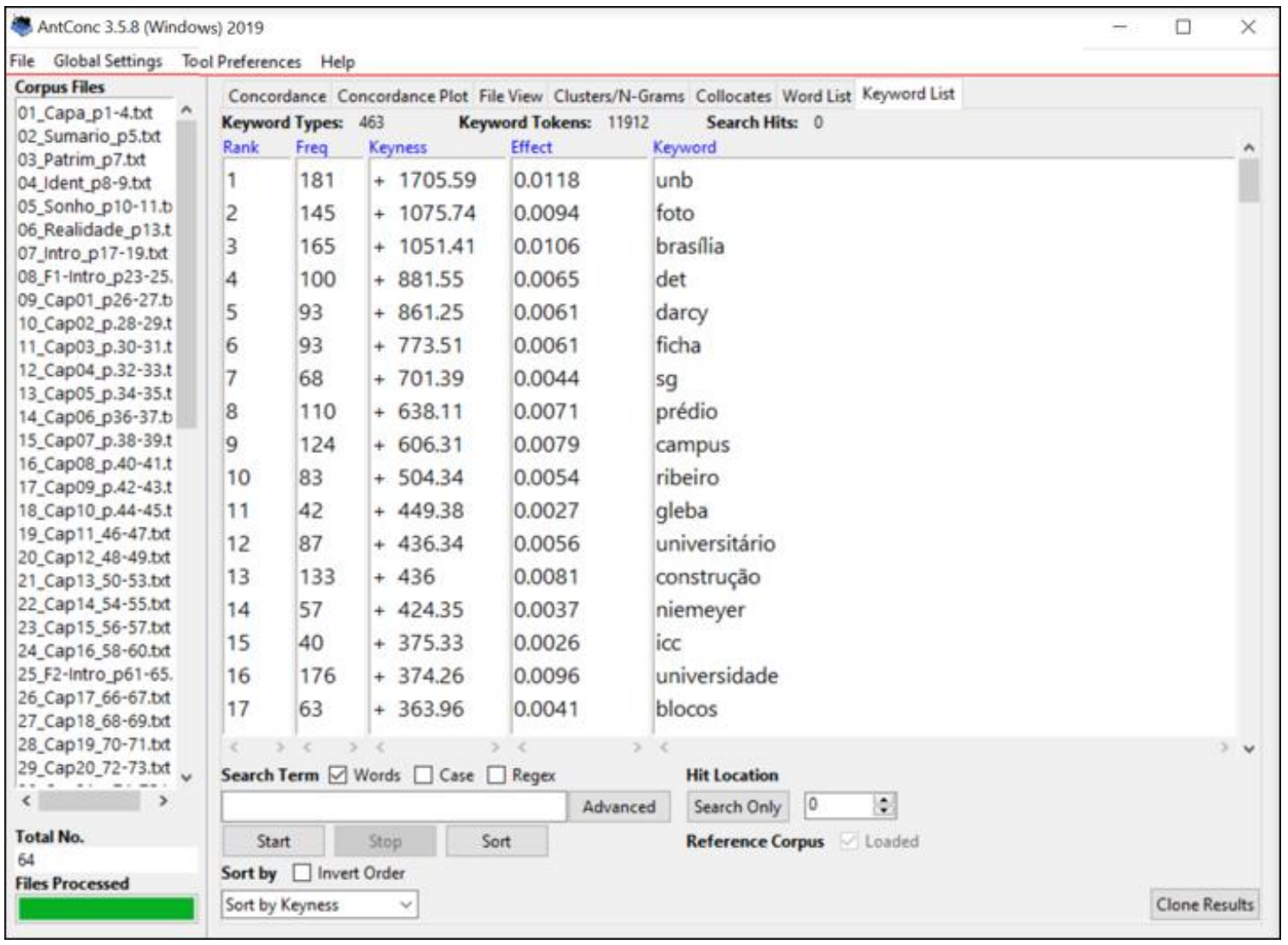

Fonte: a coautora.

A partir dessa lista, os alunos utilizaram a funcionalidade Concordance para explorar combinatórias envolvendo as palavras-chave. A tela de resultados mostra as ocorrências no corpus pesquisado de uma palavra ou expressão de busca exibindo uma linha de contexto por ocorrência, com o item centralizado e ladeado por seu contexto imediato. Esse contexto pode ser reordenado alfabeticamente pelas palavras da direita e/ou da esquerda, para facilitar a identificação de padrões recorrentes, como mostra a 
Figura 3.

Figura 3: Linhas de concordância para a palavra-chave "concreto" no AntConc.

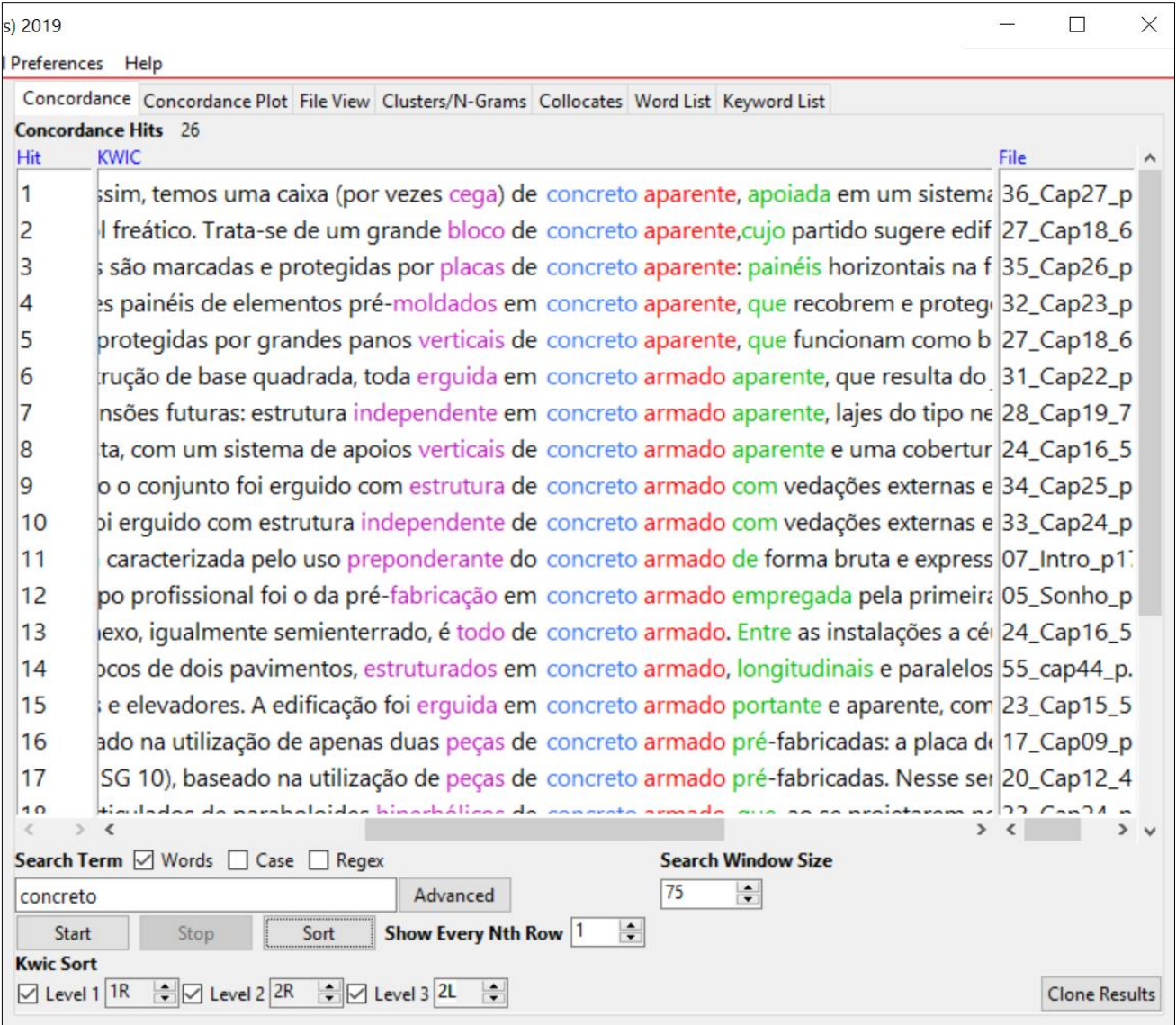

Fonte: a coautora.

Nesse percurso, os alunos identificaram três áreas problemáticas principais dentre os termos e combinatórias lexicais levantados:

i) terminologia da arquitetura (p. ex.: "anel de compressão", "telha calandrada”, “contraflexa”, “engastada”);

ii) nomes de institutos, departamentos, laboratórios e demais unidades institucionais (p. ex.: “Auditório Dois Candangos",

TradTerm, São Paulo, v.37, n. 1, janeiro/2021, p. 88-118 Número Especial - Linguística de Corpus www.revistas.usp.br/tradterm 
"Beijódromo", “Centro Integrado de Ensino Médio", “Oca”);

iii) unidades de tradução da língua geral ou semiespecializadas de difícil tradução (p. ex.: "aula magna", "regime de mutirão", "gambiarra", "formação básica”).

Cada área se transformou em um glossário na ferramenta TAC utilizada, que foram alimentados com novas entradas ao longo da atividade tradutória.

Com essas informações iniciais em mãos, a equipe responsável pela compilação do corpus selecionou algumas unidades, buscou equivalentes em inglês para as mesmas e as utilizou para fazer buscas manuais na Internet por textos de temática semelhante na língua de chegada. A meta inicial era coletarmos cerca de 300.000 palavras.

Os arquivos encontrados, a maioria em formato .pdf, foram convertidos para o formato .txt com codificação Unicode UTF-8, para facilitar sua exploração com o AntConc durante a tarefa tradutória, e acrescentados a uma nova pasta no Google drive. Quando o corpus comparável na língua de chegada atingiu o tamanho inicial planejado, iniciou-se a tradução em si.

\subsection{A tradução colaborativa em rede}

Após fazermos uma análise de diversas ferramentas de auxílio à tradução, optamos por utilizar o SmartCat ${ }^{4}$, uma plataforma online gratuita baseada em nuvem que reúne várias ferramentas TAC úteis ${ }^{5}$. Seu diferencial é um sistema de gerenciamento de projetos que permite total controle das várias etapas da tradução, além do uso integrado de glossários e memória de tradução, que são atualizados em tempo real, e um canal de comunicação direto entre os participantes do projeto.

Para começar a trabalhar nesse ambiente é preciso criar um projeto e, dentro dele, criar ou importar uma memória de tradução e um glossário, seguindo o passo a passo da plataforma. Em seguida, deve-se importar o(s)

\footnotetext{
${ }^{4}$ Disponível em: www.smartcat.ai/.

${ }^{5}$ Para um tutorial de como criar uma tarefa como esta no SmartCat, vide 0 uso de SmartCAT na tradução colaborativa e em seu ensino, disponível em:

http://termitradico.unb.br/tutoriais.
}

TradTerm, São Paulo, v.37, n. 1, janeiro/2021, p. 88-118

Número Especial - Linguística de Corpus www.revistas.usp.br/tradterm 
texto(s) de partida. Uma vez nesse ambiente, o(s) arquivo(s) pode(m) ser atribuído(s) a um ou mais tradutores, momento em que o gerente de projeto determina as datas de entrega para cada etapa (que podem ser alteradas, posteriormente). O programa aceita até quatro fases no projeto: translating, editing, proofreading e postediting - o que foi de extrema valia para o sistema de revisão em várias etapas planejado inicialmente. 0 progresso dos participantes pode ser observado em tempo real, como mostra a Figura 4:.

Figura 4:Tela de gerenciamento de projeto de tradução no SmartCAT.

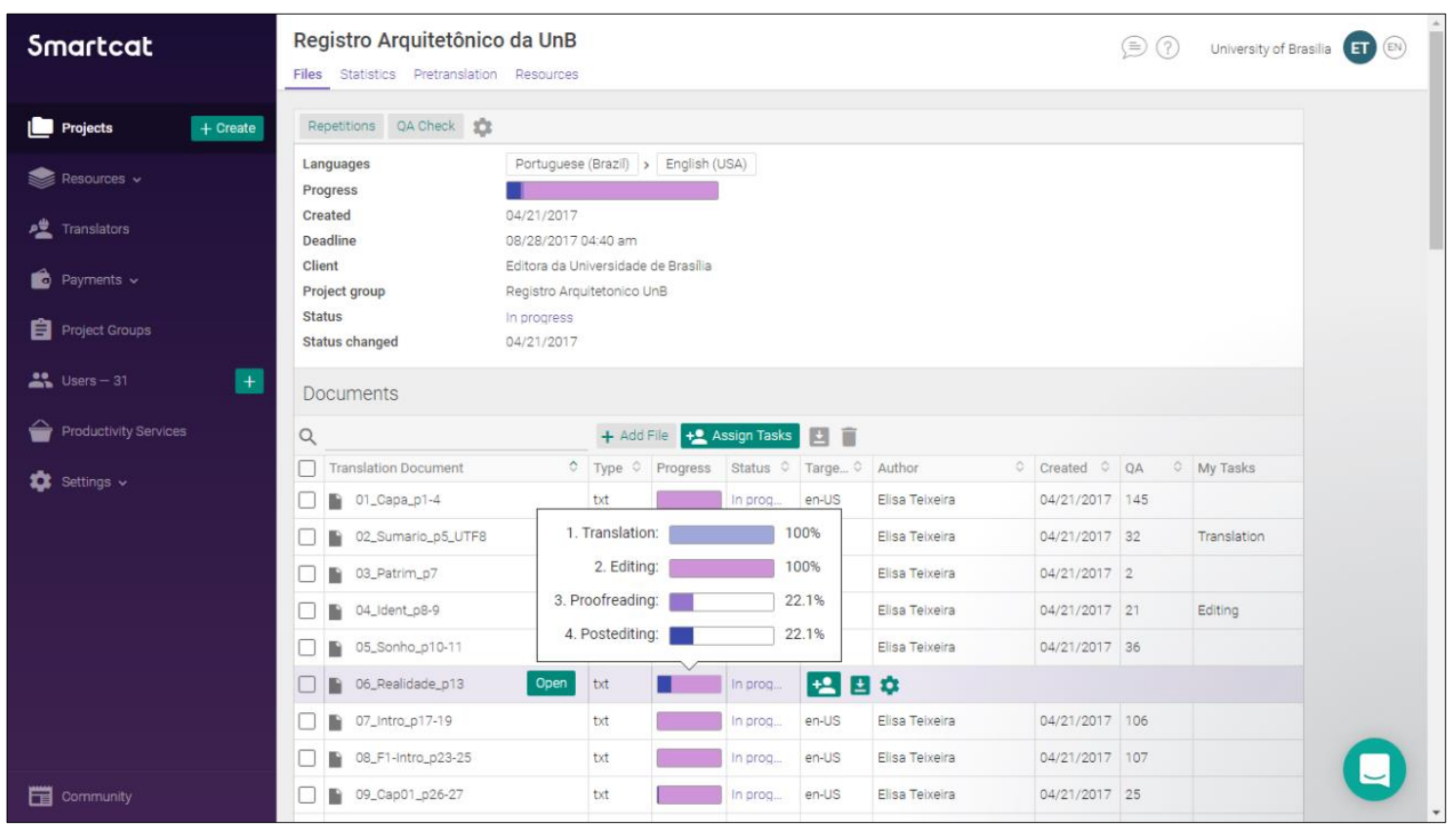

Fonte: a coautora.

Cada tradutor recebe um link para participar do projeto e pode começar a trabalhar imediatamente, momento em que um segundo ambiente da plataforma entra em cena. Embora se assemelhe a qualquer outra ferramenta TAC do mercado, tem um design bem simples e intuitivo e várias funcionalidades interessantes para quem trabalha em grupo - em especial, para quem pretende usar essa ferramenta no ensino de tradução. Na parte inferior da tela, por exemplo, é mantido um histórico completo de tudo o que acontece com cada segmento do texto de chegada, uma vez que o tradutor o confirma: se ele veio direto da tradução automática (que fica no canto superior direito e pode ser ativada ou não pelo gerente de projeto) ou se o tradutor fez alterações antes de aceitá-lo (e quais foram), quem revisou o 
segmento posteriormente, em que data, e que mudanças fez, além de permitir que sejam gravados comentários para o texto como um todo ou para segmentos específicos, estabelecendo, assim, uma interação e um diálogo ricos entre todos que estão trabalhando no mesmo texto, como mostra a

Figura 5: .

Figura 5: Tela do ambiente de Tradução Assistida por Computador do SmartCAT.

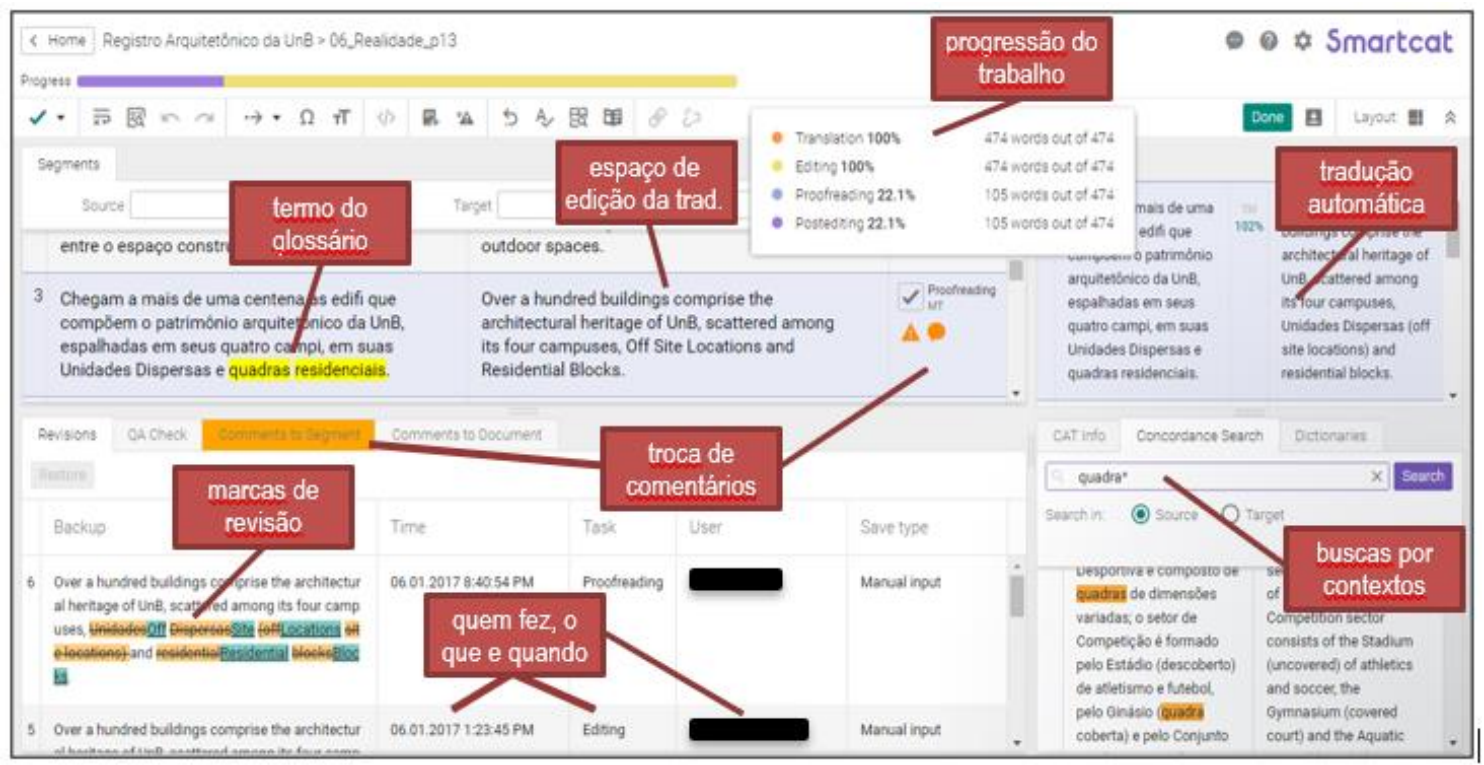

Fonte: a coautora.

Uma vez que o aluno finaliza seu trabalho, acrescentando os novos termos que surgiram ao glossário, e clica no botão verde "Done" ("Concluído", no canto superior direito), o documento passa para as mãos da pessoa responsável pela próxima etapa do processo, não podendo mais ser alterado por quem concluiu. O documento pode ser baixado em vários formatos e em qualquer uma das etapas, tanto o texto traduzido quanto uma versão paralela alinhada. No formato planejado para o projeto em questão, após passar pelo crivo dos quatro alunos envolvidos (tradutor, revisor 1 , revisor 2 e revisor 3), o texto na língua de chegada passava por uma última leitura do tradutor e era enviado para a docente, no formato paralelo arquivo utilizado, entre outras coisas, para avaliar o desempenho do aluno na disciplina, ao final do semestre.

TradTerm, São Paulo, v.37, n. 1, janeiro/2021, p. 88-118 Número Especial - Linguística de Corpus www.revistas.usp.br/tradterm 


\subsection{O processo de revisão e publicação}

Cada aluno revisou, além de seu próprio texto, a tradução de três colegas, pelo menos - de seu parceiro de dupla e dos dois alunos da outra dupla. Como preparação para esta etapa, o tema da revisão de tradução foi tratado em sala de aula, com o apoio do texto de Mossop (2014). Os alunos também foram apresentados aos instrumentos de avaliação de tradução, de autoavaliação e de avaliação do trabalho em grupo propostos por Galán-Mañas (2011), que os auxiliaram no cumprimento dessas tarefas.

Após receber as versões finais das traduções dos alunos, a docente fez uma última leitura do texto de chegada, fazendo as últimas correções necessárias. Em seguida, usou parte do pagamento para contratar uma tradutora recém-formada pelo mesmo bacharelado para ajudar na gestão da revisão e uniformização terminológica final, a ser feita com a ajuda de uma especialista da área contactada pela editora - uma das autoras da obra original. Ela foi auxiliada por outros dois alunos da turma, que demonstraram interesse em participar dessa fase do processo.

A versão final foi entregue para a equipe editorial, que fez ainda mais uma revisão, enviando os comentários e dúvidas finais para a docente e coautora deste trabalho, bem como para a responsável pela revisão terminológica. Por fim, o texto traduzido em sua versão final foi colocado no layout de impressão e enviado, uma última vez, para os tradutores. Em todas essas fases, os alunos participaram das decisões, fazendo sugestões e contribuindo para solucionar os problemas levantados, de várias maneiras.

\subsection{Resultados}

Apesar de todas as dificuldades e de todo o trabalho envolvido, consideramos que o projeto foi muito bem sucedido - o livro foi impresso em 2019 (SCHLEE 2018). Isso se deu, a nosso ver, em grande parte por conta do feedback constante em sala de aula e das discussões profícuas sobre os principais problemas enfrentados, que poderiam ser resumidos a quatro categorias: problemas de tradução em si, gestão de terminologia, dificuldades

TradTerm, São Paulo, v.37, n. 1, janeiro/2021, p. 88-118 Número Especial - Linguística de Corpus www.revistas.usp.br/tradterm 
na revisão e percalços do trabalho colaborativo. Para dar um exemplo concreto, alguns alunos não conseguiram cumprir seus prazos, atrasando toda a cadeia de etapas planejadas e exigindo um remanejamento do trabalho.

Problemas com a usabilidade da ferramenta incluíram a impossibilidade de acrescentar novos termos ao glossário automaticamente - todos tinham que passar pela aprovação do gerente de projeto (a docente), o que muitas vezes prejudicava o andamento da tradução. Mudar as datas e redistribuir textos é mais trabalhoso do que estabelecê-los inicialmente, e somente o gerente de projeto pode fazê-lo, além de várias outras funções mais administrativas. Isso gerou uma sobrecarga de trabalho para a docente que prejudicou, em alguns momentos, o andamento do projeto.

A padronização terminológica foi outro problema difícil de contornar, já que alguns equivalentes concorrentes existiam até mesmo dentro de fontes oficiais confiáveis (p. ex. nomes de departamentos). Por fim, por conta da tradução de terminologias específicas da arquitetura local, bem como de outras não encontradas no corpus inicialmente compilado, foi preciso que os alunos coletassem mais textos para o corpus monolíngue e também um pequeno corpus paralelo, com alguns textos sobre a arquitetura peculiar da UnB e/ou de Brasília, escritos originalmente em português brasileiro e suas respectivas traduções em língua inglesa.

O corpus comparável final compilado conta com 639.157 tokens (palavras-ocorrência) e 27.049 types (palavras-forma), embora mais da metade do conteúdo consista de um dicionário de arquitetura e construção. 0 corpus paralelo conta com dois livros e alguns materiais de divulgação turística na forma de livretos. Somando os três glossários, coletamos cerca de 350 termos no decurso da tradução; um deles, Glossário português $\rightarrow$ inglês de unidades acadêmicas já está disponível online para consultas ${ }^{6}$.

Dentre os muitos aspectos positivos da experiência, podemos citar a grande motivação dos alunos para trabalhar no projeto - apenas um não foi capaz de finalizar sua parte, a partir do meio do projeto, por problemas

\footnotetext{
${ }^{6}$ http://termitradico.unb.br/recursos/2-publicacoes/54-glossario-unidades-unb.
} 
pessoais, mas colegas de outras duplas se ofereceram para ajudar. Da mesma forma, apesar da grande resistência inicial em trabalhar "em grupo", alunos que terminaram suas tarefas antes do prazo se ofereceram para ajudar os colegas e a docente no que fosse possível. Além disso, os alunos foram identificando, aos poucos, os pontos fortes e fracos de seus colegas, ajudando uns aos outros para preencher as lacunas, com um verdadeiro espírito coletivo e colaborativo. Isso pode ser uma prova de que, ao final da experiência, tenham percebido que o trabalho em equipe talvez não seja "tão ruim" assim.

\section{Considerações finais}

Neste artigo apresentamos duas formas de deslocar tanto o professor de seu papel de detentor do conhecimento quanto os alunos de sua posição de meros receptáculos de informação. Essa mudança de paradigma não é fácil para nenhum dos dois, mas o emprego de metodologias ativas pode nortear a construção de projetos pedagógicos de disciplinas de prática de tradução. A LC, bem como o uso de outras ferramentas informatizadas, em muito contribuem para facilitar essa nova dinâmica de sala de aula, tornando-a mais factível e proveitosa para docentes e aprendizes.

Descrevemos aqui duas possibilidades de interação dentro da sala de aula que visam empoderar os alunos e permitir que assumam o controle de sua aprendizagem. Inicialmente sugerimos uma metodologia de atividade que envolve o aluno em todos os passos. A escolha e seleção dos textos, sob orientação do professor, é feita pelo discente. As traduções feitas pelos alunos são enviadas para o professor via Formulário Google, que automaticamente gera uma planilha eletrônica. A forma como o texto de partida e as traduções são acomodadas gera um corpus paralelo alinhado, que pode ser facilmente analisado por meio do uso dos filtros textuais do programa. Os resultados das pesquisas são usados para traçar um perfil de conhecimento linguístico dos alunos e para orientar o planejamento da aula, pois mostram ao professor quais pontos devem ser abordados. 0 mesmo corpus disposto na planilha eletrônica é usado também como material didático durante a aula. Juntamente com os alunos, o professor analisa cada TradTerm, São Paulo, v.37, n. 1, janeiro/2021, p. 88-118 Número Especial - Linguística de Corpus 
trecho e promove a discussão sobre as traduções. Por fim, alunos e professor fazem uma avaliação da atividade, abordando questões sobre a tarefa e avaliando se as estratégias adotadas foram ou não eficientes.

Em um segundo momento, apresentamos uma experiência didática baseada em projeto em que uma turma de prática de tradução de textos especializados assumiu, juntamente com a professora, a responsabilidade por um projeto real de tradução, realizada ao longo do semestre, de forma colaborativa. 0 uso de corpora, juntamente com o processo de revisão em várias etapas propiciado pelo uso do SmartCAT (cada tradução passou pelo crivo de pelo menos três alunos, do próprio tradutor e da docente antes de ser submetido à editora), foram o que garantiu uma boa qualidade do material entregue, apesar da pouca experiência da turma e do desconhecimento da área especializada. Nesse sentido, a contratação de uma tradutora recém-formada para resolver problemas pontuais de terminologia junto a uma especialista da área também foi uma decisão acertada.

Apesar do grande trabalho demandado para a execução do projeto, os ganhos foram evidentes. Os alunos demonstraram grande motivação nas aulas e no cumprimento das tarefas designadas e se mostraram mais confiantes em seu futuro profissional ao final do semestre. Por fim, outra grande vantagem é que já temos autorização para uso em pesquisa de todo o material resultante: original e as várias versões do texto traduzido. Esperamos poder disponibilizálo na forma de um corpus multiversão de aprendizes consultável, em breve. Outra ideia seria trabalhar mais nos outros dois glossários resultantes e publicá-los online, para que mais pessoas possam consultá-los também.

Esperamos ter demonstrado que é viável a implementação de metodologias ativas em aulas de prática de tradução, especialmente quando associadas ao uso de corpora e ferramentas de TAC. Além de incentivarem o protagonismo dos alunos, essas metodologias capacitam o futuro tradutor, preparando-o para um mercado de trabalho em constante evolução tecnológica.

TradTerm, São Paulo, v.37, n. 1, janeiro/2021, p. 88-118 Número Especial - Linguística de Corpus www.revistas.usp.br/tradterm 


\section{Referências}

Aluísio, S. M.; Pinheiro, G.; Finger, M.; Nunes, M. G. V.; Tagnin, S. E. O. The Lácio-Web Project: overview and issues in Brazilian Portuguese corpus creation. In: Proceedings of Corpus Linguistics 2003. Lancaster, UCREL: Lancaster University, 2003, pp. 14-21.

ANTHONY, L. AntConc [Software] (Version 3.4.2). Tokyo, Japão: Waseda University, 2014. Disponível em http://www.laurenceanthony.net/. $(14 / 3 / 2020)$.

BAKER, M. In Other Words: A coursebook on translation. London/New York: Routledge, 1992.

BAKER, M. Corpus linguistics and translation studies. Implications and applications. In: BAKER, M.; FranCIS, G.; TOGNINI-BONELLI, E. (Ed.). Text and technology. In honour of John Sinclair. Amsterdam: John Benjamins, 1993, pp. 233-250.

Barreiro, A. B.; Ling, W.; Coheur, L.; Batista, F.; Trancoso, I. Projetos sobre Tradução Automática do Português no Laboratório de Sistemas de Língua Falada do INESC-ID. Linguamática, 6, n. 2, dez 2014, p. 75-85.

Berber Sardinha, T. Lingüística de Corpus. São Paulo: Manole, 2004.

Bergmann, J.; SAmS, A. Flip Your Classroom: Reach every student in every class every day. Eugene, Oregon: International Society for Technology in Education, 2012.

ColinA, S.; VENUTI, L. A survey of translation pedagogies. In: VenUTI, L. (Ed). Teaching Translation: Programs, Courses, Pedagogies. London / New York: Routledge, 2017, pp. 203-215.

Drouin, P. TermoStat Web (Version 3.0) [Ferramenta Online]. Montreal, Canada: Université de Montréal, 2003. Disponível em http://termostat.ling.umontreal.ca/index.php?lang=en_CA. Acesso em: 14 mar. 2020.

DuRBAn, C.; MelBY, A. Translation: Buying a non-commodity. London: Institute of Translation and Interpreting, 2007.

EsquedA, M. D. Ensino de tradução: culturas pedagógicas. Trabalhos em linguística aplicada, v. 57, n. 2, ago. 2018, pp. 1244-1273. doi:http://dx.doi.org/10.1590/010318138651880364601

GALÁN-MAÑAS, A. Translating authentic technical documents in specialised translation classes. Translated by Roland Pearson. The Journal of Specialised Translation Issue 16. July 2011, pp. 109-125.

GonçAlVES, L. B. 'Dubliners' sob a lupa da Lingüística de Corpus: uma

TradTerm, São Paulo, v.37, n. 1, janeiro/2021, p. 88-118

Número Especial - Linguística de Corpus

www.revistas.usp.br/tradterm 
contribuição para a análise e a avaliação da tradução literária. Tese (Doutorado em Estudos Lingüísticos e Literários em Inglês) - Faculdade de Filosofia, Letras e Ciências Humanas, Universidade de São Paulo, São Paulo, 2006.

González-DaVies, M. (Ed). Secuencias. Tareas para el Aprendizaje Interactivo de la Traducción Especializada. Barcelona: Octaedro, 2003.

González-DaVies, M. Multiple voices in the translation classroom: activities, tasks and projects. Amsterdam/Philadelphia: John Benjamins, 2004.

González-DaVIES, M. A collaborative pedagogy for translation. In: VenUtI, L. (Ed.). Teaching Translation: Programs, Courses, Pedagogies. London / New York: Routledge, 2017, pp. 71-78.

GouadeC, D. Position Paper: Notes on Translator Training. In: PyM, A.; FalladA, C.; RAMón, J. B.; ORENSTEIN, J. (Ed.). Innovation and e-Learning in Translator Training. Tarragona: Universitat Rovira i Virgili, 2003, pp. 11-19.

GRANGER, S. Learner corpora. In: LüdeLING, A.; KYTÖ, M. Corpus Linguistics. An International Handbook, v. 1. Berlin/New York: Walter de Gruyter, 2008, pp. 259-275.

HURTADO AlBIR, A. Enseñar a traducir. Metodología en la formación de traductores e intérpretes. Madrid: Edelsa, 1999.

HYUn, J.; EDIGER, R.; LEE, D. Students' satisfaction on their learning process in active learning and traditional classrooms. International Journal of Teaching and Learning in Higher Education, Purdue, v. 29, 2017, pp. 108-118. http://www.isetl.org/ijtlhe/. Acesso em: 15 mar. 2020.

Instituto nacional de Estudos e Pesquisas Educacionals anísio teixeira. Disponível em Censo Escolar da Educação Superior - 2008, 2008. http://portal.inep.gov.br/web/guest/sinopses-estatisticas-daeducacao-superior. Acesso em: 20 jan. 2020.

Instituto nacional de Estudos e Pesquisas Educacionals anísio teixeira. Disponível em Censo Escolar da Educação Superior - 2018, 2018. http://portal.inep.gov.br/web/guest/sinopses-estatisticas-daeducacao-superior. Acesso em: 20 jan. 2020.

JOHANSSON, S. On the role of corpora in cross-linguistic research. In: JOHANSSON, S.; OKSEFJELL, S. (EDS). Corpora and Cross-linguistic Research. Amsterdam / Atlanta: Rodopi, 1998, pp. 1-24.

KELLY, D. A handbook for translator trainers: A guide to reflexive practice. Manchester, UK \& Northampton, MA: St. Jerome Publishing, 2005.

KIRALY, D. From Teacher-Centered to Learning-Centered Classrooms in Translator Education. Across Languages and Cultures, v. 1, n. 2, 2000,

TradTerm, São Paulo, v.37, n. 1, janeiro/2021, p. 88-118

Número Especial - Linguística de Corpus www.revistas.usp.br/tradterm 
pp. 239-244.

KIRALY, D. Project-Based Learning: A Case for Situated Translation. META 50.4, 2005, pp. 1098-1111.

KIRALY, D. Growing a Project-Based Translation Pedagogy: A Fractal Perspective. META. v. 57, n. 1, 2012, pp. 82-95.

Olohan, M. Scientific and Technical Translation. New York: Routledge, 2016.

MAIA, B. Do-it-yourself, disposable, specialised mini corpora - where next? Reflections on teaching translation and terminology through corpora. In: TAGnIN, S. E. O. (Org.) Cadernos de Tradução no. 9, 2002/1. Florianópolis: Núcleo de Tradução da Universidade Federal de Santa Catarina, 2002, pp. 221-235.

MALTA, G.; TeIXEIRA, E.D. Estágio Supervisionado de Tradução junto ao Projeto "Tradução e Internacionalização": Proposta e resultados preliminares. In: Pereira, G. H.; Costa, P. R. (Org.) Os desafios da formação de tradutores no Brasil: Passado, presente e futuro. Campinas: Pontes Editores (Col. Estudos da Tradução, vol. 9), no prelo.

MORÁn, J. Mudando a educação com metodologias ativas. In: SouZA, C. A. D.; MORALES, O. E. T. (Orgs). Convergências Midiáticas, Educação e Cidadania: aproximações jovens, Ponta Grossa, v. III, 2015, pp.15-33. Disponível em: https://www.ucs.br/site/midia/arquivos/bibliografiaPGCIMA-canela.pdf. Acesso em: 25 mar. 2020.

Mossop, B. Revising and Editing for Translators (Translation Practices Explained). Manchester, UK / Kinderhook (USA): St. Jerome Publishing, 2014 [2001].

OliVEIRA, J. T. A Linguística de Corpus na formação do tradutor: compilação e proposta de análise de um corpus paralelo de aprendizes de tradução. 147 f. Dissertação (Mestrado em Estudos Linguísticos e Literários em Inglês). Universidade de São Paulo. Departamento de Letras Modernas, São Paulo, 2014.

Oliveira, J. T. (2019). Um corpus de aprendizes de tradução: compilação, tratamento e aplicação ao ensino por meio de planilha eletrônica. Tese, 259 f. Tese (Doutorado em Estudos Linguísticos e Literários em Inglês) Universidade de São Paulo. Departamento de Letras Modernas, Doutorado em Estudos Linguísticos e Literários em Inglês. Departamento de Letras Modernas, São Paulo.

PACTE. Building a translation competence model. In: ALVES, F. (Ed.). Triangulating translation: perspectives in process, 2003, pp. 43-66.

Schlee, A. R.; Garcia, C. C.; Soares, E. O.; Tenorio, G. S.; Nascimento, M. L. C.; VULCÃO, M. G. V.; ChOAS, M. L. L. S. Registro arquitetônico da Universidade de Brasília. Brasília, DF: Editora da Universidade de TradTerm, São Paulo, v.37, n. 1, janeiro/2021, p. 88-118 Número Especial - Linguística de Corpus www.revistas.usp.br/tradterm 
Brasília, 2014.

SCHLeE, A. R. ET AL. Architectural Record of the University of Brasilia. Tradução: TeIXEIRA. E.D. (Coord.), FaRIAS, A. L. C.; Menezes, A. D. M.; Sobral, B. H.; Sepulveda, C. B.; Araujo, C. A. G.; Ferreira, D. S.; Lima, E. P.; Studart, F. C. S.; Barbosa, I. M. M.; Goncalves, I. C. C.; Moura, J. V. G.; Perez, L. B.; Santos, M. F. M.; Ruivo, M. A.; Servan, P. F.; Barbosa Junior, P. R.; MARTINS, R. R.; CATALDI, S. P.; AbReU, T. G. L.; CRUZ, L. R. S. Brasília, DF: Editora da Universidade de Brasília, 2018.

SmartCAT [Ferramenta Online]. Disponível em: http://www.smartcat.ai. Acesso em: 30 mar. 2020.

SINCLAIR, J. M. Corpus, Concordance, Collocation. Oxford: Oxford University Press, 1991.

TAGNIN, S. E. O. A Linguística de Corpus na e para a tradução. In: VIANA, V.; TAGNIN, S. E. O. (Orgs). Corpora na tradução. São Paulo: Hub Editorial, 2015, pp. 19-56.

TogninI-BonelLI, E. Corpus Linguistics at Work. Amsterdam: John Benjamins, 2001.

VARANTOLA, K. Disposable corpora as intelligent tools in translation. In: TAGNIN, S. E. O. (Org.) Cadernos de Tradução no. 9, 2002/1. Florianópolis: Núcleo de Tradução da Universidade Federal de Santa Catarina, 2002, pp. 171-189.

VenUtI, L. (Ed). Teaching Translation: Programs, Courses, Pedagogies. London/New York: Routledge, 2017.

Viana, V.; Tagnin, S. E. O. (Org.). Corpora na tradução. São Paulo: Hub Editorial, 2015.

VIENNE, J. Towards a pedagogy of "translation in situation". Perspectives, v. 2, n. 1, 1994, pp. 51-59.

Recebido em: 30/04/2020

Aceito em: 26/05/2020

Publicado em janeiro de 2021

TradTerm, São Paulo, v.37, n. 1, janeiro/2021, p. 88-118

Número Especial - Linguística de Corpus

www.revistas.usp.br/tradterm 